\title{
Mechanism and Kinetics of Stabilization Reaction of Polyacrylonitrile and Related Copolymers V. The Change in Birefringence of Acrylonitrile/Methacrylic Acid Copolymer Fibers by Heat Treatment under Fixed Length
}

\author{
Hideto $\mathrm{KAKIDA}^{\dagger}$ and Kohji TASHIRO* \\ Central Technology Research Laboratories, Mitsubishi Rayon Co., Ltd., \\ Otake, Hiroshima 739-0693, Japan \\ * Department of Macromolecular Science, Graduate School of Science, \\ Osaka University, Toyonaka, Osaka 560-0043, Japan
}

(Received October 20, 1997)

\begin{abstract}
Relationships between birefringence change and structural change of the acrylic precursor fibers, made of acrylonitrile/methacrylic acid copolymer during stabilization reaction in air, were investigated to clarify the causes of birefringence change. The birefringence changed from slightly negative to highly positive by heat treatment at $200^{\circ} \mathrm{C}$. The wide-angle X-ray pattern did not change essentially, showing apparently no fiber structure change. The IR spectra clarified the remarkable chemical structure change and resultant formation of the fully aromatic cyclised structure, which is considered the cause for increase of birefringence.

KEY WORDS Birefringence/Wide-Angle X-Ray Photograph / Fourier Transform Infrared Spectroscopy

/ Acrylic Precursor Fiber / Fully Aromatic Cyclized Structure / Carbon Fiber /
\end{abstract}

Acrylic fibers made of polyacrylonitrile (PAN) containing acidic comonomers like methacrylic acid, itaconic acid and acrylic acid are the most commonly used precursors for carbon fibers because of excellent performance of PAN based carbon fibers. ${ }^{1}$

In PAN based carbon fiber production, stabilization is most important, because the physical properties of carbon fibers are affected significantly by the conditions of stabilization. A lot of studies have been reported concerning the stabilization of PAN since $1950 .^{2,3}$ According to these studies, acrylic fibers are converted into infusible and nonflammable fibers by heating at 200 $300^{\circ} \mathrm{C}$ for about $1 \mathrm{~h}$ in an oxidative atmosphere during stabilization. Only the fibers thus stabilized can be heated to carbonization temperatures $\left(1000-2000^{\circ} \mathrm{C}\right) .^{4}$

The mechanism of stabilization reaction has been studied by many workers. Houts ${ }^{5}$ postulated a conjugated, fully heteroaromatic cyclic structure to account for changes taking place during degradation, such as coloration, insolubility and flame resistance. This cyclization concept was adopted in modified form by many subsequent workers. Grassie et al., ${ }^{6}$ Burlant and Parsons, ${ }^{7}$ LaCombe ${ }^{8}$ modified Houtz's cyclization scheme to a partially aromatic structure and this has become the most popular reaction scheme currently quoted in many textbooks. ${ }^{9}$ This partially aromatic structure is also called a ladder polymer. ${ }^{2}$ However, Schurz proposed an azomethine crosslinking reaction to explain the insolubility of stabilized PAN. ${ }^{10}$ Berlin et al. ${ }^{11}$ and Fester ${ }^{12,13}$ believe that hydrogen elimination leads to a conjugated polyene with pendant nitrile groups. As above mentioned, cyclization is thought to be a well established scheme, but it is said that there is still no direct evidence for a cyclization mechanism. ${ }^{2}$

We have studied the mechanism of stabilization reaction of PAN and related copolymers by means of an organized combination of isothermal DSC thermogram and FT-IR spectra. ${ }^{3,14-17}$ The initiation of the cyclization reaction by the acidic comonomer, the relationship of heat evolution and changes of the chemical structure of the polymer chain, and efficiency of comonomers for accelerating stabilization reaction were clarified by these studies. ${ }^{3,14,15}$ We interpreted reasonably the structural changes during stabilization reaction under oxidative atmosphere in such a way that the partially cyclised aromatic structure is formed by the nitrile polymerization at an early time, and immediately after that the structure changes to the fully aromatic cyclized structure by the dehydrogenation of the backbone followed by the introduction of oxygen atoms into the molecule. $^{17}$

Thorn and Marjoram ${ }^{18}$ reported that acrylic fibers containing methylacrylate comonomer exhibit an increase of birefringence and a decrease of X-ray diffraction orientation parameter by heat treatment under fixed length in the temperature range $200-300^{\circ} \mathrm{C}$ in an inert environment. They explained this inverse correlation of birefringence and X-ray orientation parameter in such a way that the $\mathrm{X}$-ray parameter reflected the orientation of the residual polyacrylonitrile sequences whereas the positive birefringence reflected the orientation of the new polymer species formed during stabilization reaction.

In our studies, the usefulness of infrared spectroscopy was confirmed so as to clarify structural changes occurring in the acrylic precursor fibers. This paper investigates the changes of the birefringence of the acrylic precursor fibers induced by heat treatment in air at 160 and $200^{\circ} \mathrm{C}$ and related them to the IR spectral changes. By combining these spectroscopic data with X-ray diffraction data, we could get more detailed information on the stabilization reaction.

† To whom correspondence should be addressed. 


\section{EXPERIMENTAL}

\section{Materials}

The precursor fibers were made of the acrylonitrile (AN) copolymer, which contained about one mole percent of methacrylic acid (MAA) and was polymerized by aqueous suspension polymerization with redox initiator. The weight averaged molecular weight of this copolymer was about $2 \times 10^{5}$. The precursor fibers were spun by dry-jet spinning from the dimethylformamide solution and stretched about 10 times in boiling water and then were heat treated to set the stretched structure on hot rollers controlled at $130-180^{\circ} \mathrm{C}$. The amount of residual solvent was negligibly small. The diameter of a fiber was about $10 \mu \mathrm{m}$.

\section{Stabilization Treatment}

The stabilization of the acrylic precursor fibers was carried out in a constant temperature-zone furnace, by a fixed-length method at $160^{\circ} \mathrm{C}$ for $15-180 \mathrm{~min}$ and at $200^{\circ} \mathrm{C}$ for $7-90 \mathrm{~min}$ in air atmosphere.

\section{FT-IR Measurements}

The stabilized acrylic fibers were ground into fine powder by a freezer mill at liquid nitrogen temperature. FT-IR measurements were carried out on the basis of the methods described previously. $3,14,15$

\section{Wide-Angle X-Ray Diffraction (WAXD) Photographs}

WAXD flat-plate photographs for acrylic precursor fibers and stabilized fibers were obtained with Ni-filtered $\mathrm{Cu}-K_{\alpha}$ radiation from a Rigaku X-ray generator operated at $40 \mathrm{kV}$ and $60 \mathrm{~mA}$. The sample-film distance was maintained at $4 \mathrm{~cm}$, and typical exposure time was $3 \mathrm{~h}$.

\section{Birefringence Measurements}

Birefringence $(\Delta n)$ was measured at room temperature by a Nikon polarized optical microscope. $\Delta n$ is expressed as follows:

$$
\Delta n \times d=\left(n_{\|}-n_{\perp}\right) d=(N+\delta N) \lambda=\text { retardation }
$$

where $(N+\delta N)$ is the number of wavelength $\lambda$ for which the light is retarded, and $d$ is the fiber diameter. The wavelength $\lambda$ was $546 \mathrm{~nm}$. The $N$ was obtained by counting the number of interference fringes in the oblique section of a fiber between crossed Nicol prisms. The fraction $\delta N$ was determined by using a Senarmont compensator.

\section{RESULTS AND DISCUSSION}

\section{Changes of Birefringence of Acrylic Fibers Stabilized in Air}

Figure 1 shows changes of birefringence of the precursor acrylic fibers stabilized at 160 and $200^{\circ} \mathrm{C}$ with fixed length. The birefringence increased drastically and linearly with heat treatment time at higher temperature. The birefringence of the original precursor fiber, $-3.8 \times$ $10^{-3}$, changes to nearly 0 by heat treatment for $120 \mathrm{~min}$ at $160^{\circ} \mathrm{C}$, and then attains to a positive value of $2.7 \times$ $10^{-3}$ after heat treatment for $180 \mathrm{~min}$. When the fiber was heat treated at $200^{\circ} \mathrm{C}$, the value became nearly 0 by 7 min heat treatment and increased above $90 \times 10^{-3}$ after

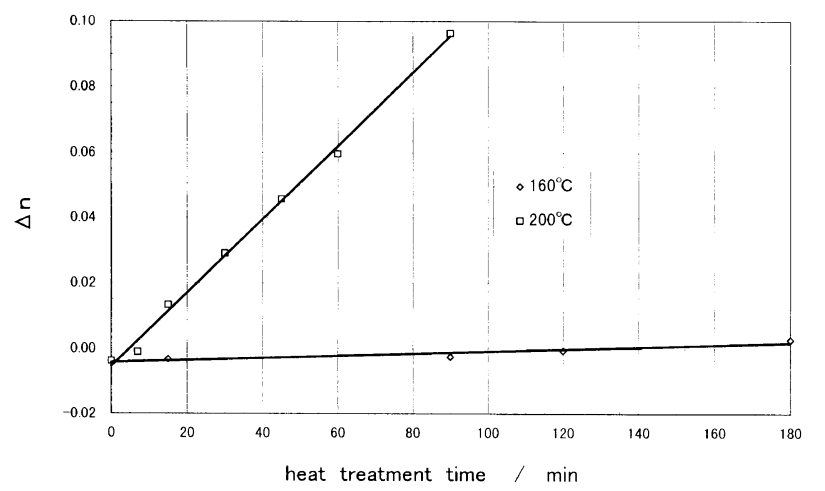

Figure 1. Changes of birefringence of precursor acrylic fibers when heat treated at 160 and $200^{\circ} \mathrm{C}$ in air atmosphere.

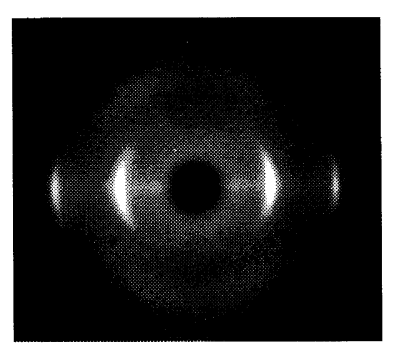

( a )

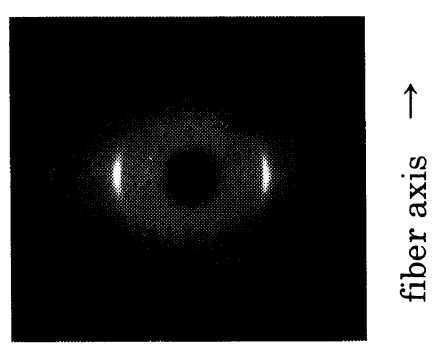

( b )
Figure 2. X-Ray diffraction photographs of precursor acrylic fibers, (a) is original and (b) is heat treated for $90 \mathrm{~min}$ at $200^{\circ} \mathrm{C}$.

$90 \mathrm{~min}$ heat treatment. The rate of increase of birefringence was larger at higher temperature.

The birefringence of the fully stretched acrylic fiber was reported to be about $-5 \times 10^{-3}$, attributed to the polarizability of pendant nitrile groups greater than those of the bonds in the main polymer chain. ${ }^{19,20}$

\section{$X$-Ray Diffraction Measurements}

Figure 2 shows the X-ray diffraction photographs of the acrylic precursor fibers. (a) is for the original and (b) sample heat treated at $200^{\circ} \mathrm{C}$ for $90 \mathrm{~min}$. The diffraction patterns are essentially the same. Therefore we may say that the fiber structure does not change during heat treatment. The X-ray orientation of the heat treated fibers is also considered to be nearly unchanged. Therefore the transition from negative $(-0.0038)$ to positive value of the birefringence (up to +0.09 ) is not thought to be caused by the fiber structure change.

Thorne and Marjoram ${ }^{18}$ reported that the orientation parameter evaluated from the arc of the X-ray 100 reflection of polyacrylonitrile decreased with thermal treatment. The drastic decrease of the orientation parameter was observed for the sample with the birefringence value higher than 0.1 , but did not decrease when the birefringence of the sample was lower than 0.1 .

The difference between our data and those of Thorne is thought to be difference in the heat treatment temperature.

\section{The IR Spectral Changes}

Figures 3 and 4 show the changes of the IR spectra during heat treatments at 160 and $200^{\circ} \mathrm{C}$, respectively. For heat-treatment at $160^{\circ} \mathrm{C}$, the IR spectra change only 


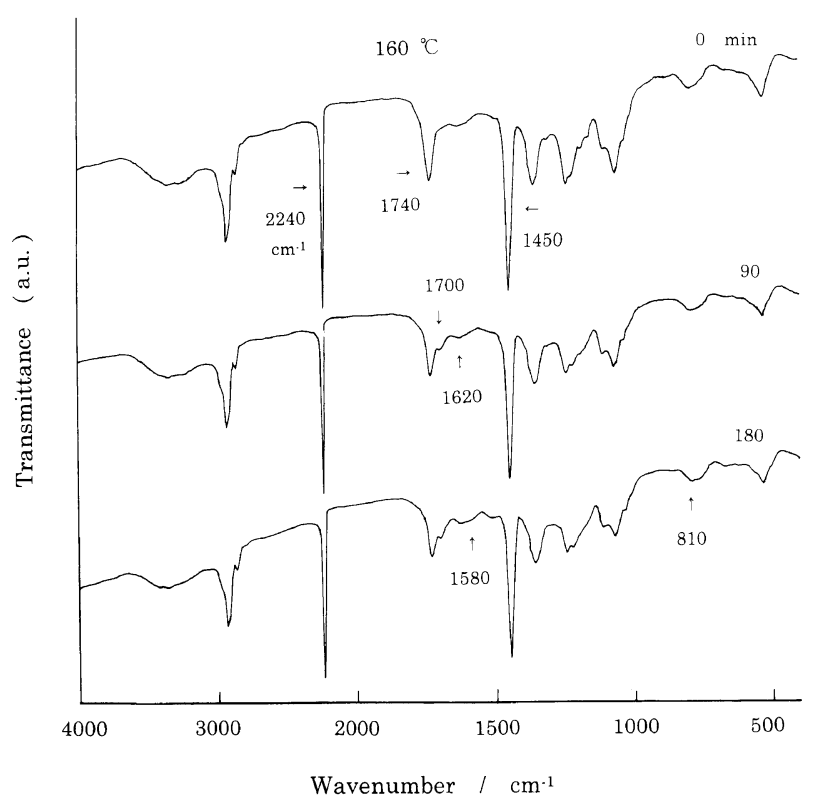

Figure 3. Change of IR spectra when heat treated at $160^{\circ} \mathrm{C}$ in air.

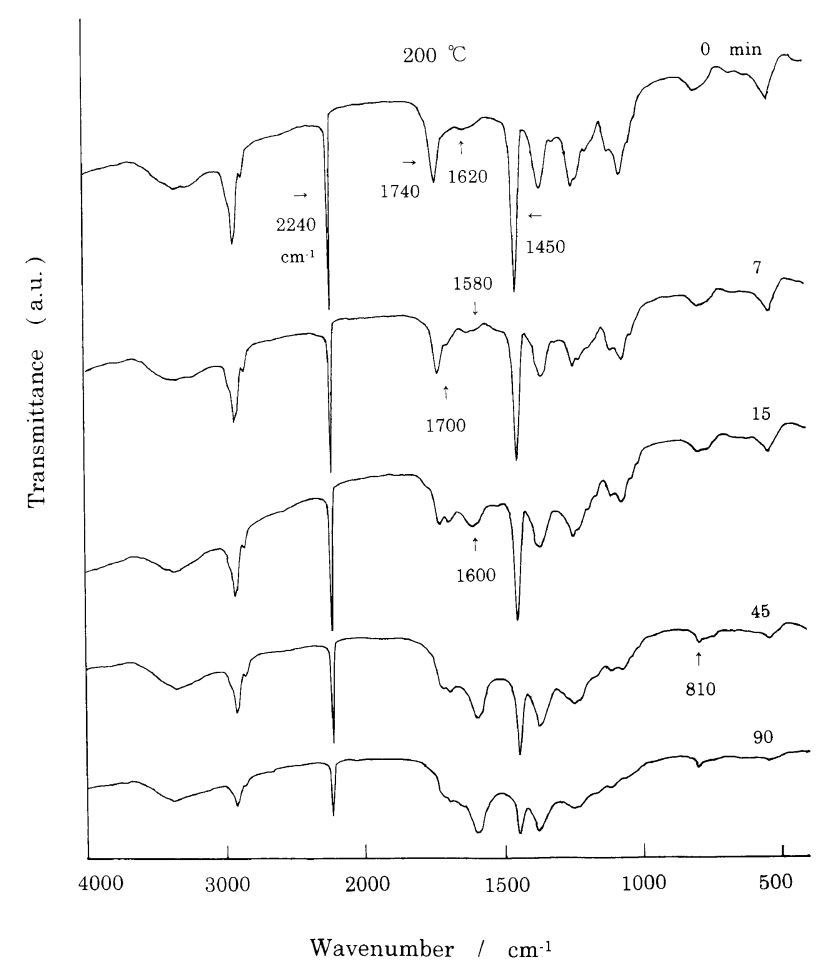

Figure 4. Change of IR spectra when heat treated at $200^{\circ} \mathrm{C}$ in air.

slightly. The $1740 \mathrm{~cm}^{-1}$ band of MAA decreases in intensity and the $1700 \mathrm{~cm}^{-1}$ band of the reacted MAA appears and grows. The $810 \mathrm{~cm}^{-1} \gamma(\mathrm{C}-\mathrm{H})$ band of $\mathrm{C}=\mathrm{C}-\mathrm{H}$ group also appears. At $200^{\circ} \mathrm{C}$, the spectral change is dramatic. The $2240 \mathrm{~cm}^{-1} v(\mathrm{C} \equiv \mathrm{N}), 1450 \mathrm{~cm}^{-1}$ $\delta\left(\mathrm{CH}_{2}\right)$ and $1740 \mathrm{~cm}^{-1} v(\mathrm{C}=\mathrm{O})$ of MAA bands decrease in intensity remarkably. The $1600 \mathrm{~cm}^{-1}$ band assigned to $v(\mathrm{C}=\mathrm{C})$ and $v(\mathrm{C}=\mathrm{N})$ of the fully aromatic cyclised structure increases remarkably in intensity. The assignments of these IR bands were based on Fochler et al. ${ }^{21}$ and Sivy et al. $^{22}$ as shown in Table I. The changes of the IR spectra seem related closely to the birefringence changes during the heat treatment, as discussed below.
Table I. Principal IR bands in solid and degraded PAN, AN/MAA, and AN/AAM

\begin{tabular}{lc}
\hline Functional groups & Wavenumber $/ \mathrm{cm}^{-1}$ \\
\hline $\mathrm{NH}_{2}$ & 3390,3356 \\
$\mathrm{NH}$ & 3230 \\
$\mathrm{CH}_{2}$ & 2945,2920 \\
$\mathrm{CH}$ & 2895 \\
$\mathrm{C} \equiv \mathrm{N}$ (saturated) & 2240 \\
$\mathrm{C}=\mathrm{O}$ (unreacted MAA) & 1740 \\
$\mathrm{C}=\mathrm{O}$ (reacted MAA) & 1700 \\
$\mathrm{C}=\mathrm{O}$ (amide) & 1680 \\
$\mathrm{~N}-\mathrm{H}($ amide) & 1620 \\
$\mathrm{C}=\mathrm{N}, \mathrm{C}=\mathrm{C}$ mixed & $1620^{\mathrm{a}}$ \\
$\mathrm{C}=\mathrm{N}, \mathrm{C}=\mathrm{C}, \mathrm{N}-\mathrm{H}$ mixed & $1580^{\mathrm{a}}$ \\
$\mathrm{CH}$ & 1450 \\
$\mathrm{CH}, \mathrm{NH}$ & 1380 \\
$\mathrm{C}-\mathrm{C}, \mathrm{C}-\mathrm{N}$ mixed & 1250 \\
$\mathrm{C}=\mathrm{C}-\mathrm{H}$ & 810 \\
\end{tabular}

a These bands are often not resolved and appear at $1600 \pm 10 \mathrm{~cm}^{-1}$

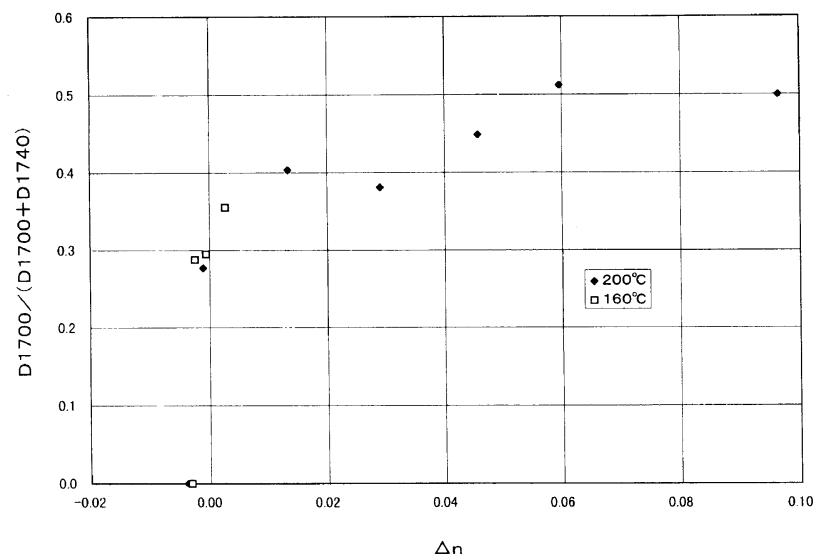

Figure 5. Relationship of D1700/(D1700+D1740) with birefringence for the heat treated precursor fibers.

\section{Relationship between Changes of Birefringence and IR Spectra Caused by Heat Treatment}

It is expected that there is an intimate relationship between the changes of birefringence and IR spectra. Figures 3 and 4 show that the molecular structures remarkably changed : the decrease of $\mathrm{C} \equiv \mathrm{N}, \mathrm{CH}_{2}$ and $\mathrm{C}=\mathrm{O}$ groups of MAA residues, and increase of $\mathrm{C}=\mathrm{O}$ of the reacted $\mathrm{MAA}, \mathrm{C}=\mathrm{C}$ and $\mathrm{C}=\mathrm{N}$ of the fully aromatic cyclised structure and $\mathrm{C}=\mathrm{C}-\mathrm{H}$ group. These molecular structural changes are caused by the initiation reaction of cyclization of MAA, the propagation of cyclic structure by nitrile polymerization and dehydrogenation of the polymer backbone. One of these reactions should be related intimately to birefringence.

Figure 5 shows the relationship between the value of $\mathrm{D} 1700 /(\mathrm{D} 1700+\mathrm{D} 1740)$, which reflects the structure change of MAA, and the birefringence, where the D1700, for example, indicates the absorbance of IR band at $1700 \mathrm{~cm}^{-1}$. In Figure 6, D810/(D810+D1450), showing the degree of the dehydrogenation reaction, is related to birefringence. Figure 7 shows the relationship between birefringence and D1600/(D1600+D2240) that shows development of cyclic and fully aromatic cyclic structures. Figure 8 shows the relationship of the birefringence with the parameter D1600/(D1600+D1450), a measure of development of the dehydrogenation and fully 
aromatic cyclic structure. In these figures, the data of 160 and $200^{\circ} \mathrm{C}$ heat treatments are shown. In the case of $160^{\circ} \mathrm{C}$ heat treatment, the two bands at 1620 and $1580 \mathrm{~cm}^{-1}$ are observed closely around $1600 \mathrm{~cm}^{-1}$, so the average between these two band intensities was used as D1600.

A good linear relationship is observed in Figures 7 and 8. The D1600/(D1600+D2240) and D1600/ $(\mathrm{D} 1600+\mathrm{D} 1450)$ are found to be related linearly with birefringence. This indicates that the birefringence increases with the development of the fully aromatic cyclic structure caused by the cyclization reaction between nitrile groups and also by the dehydrogenation reaction of polymer backbone.

In Figure 4, the IR spectrum of the sample treated for 7 min shows bands at 1620 and $1580 \mathrm{~cm}^{-1}$, indicating that the partially cyclized aromatic structure is formed

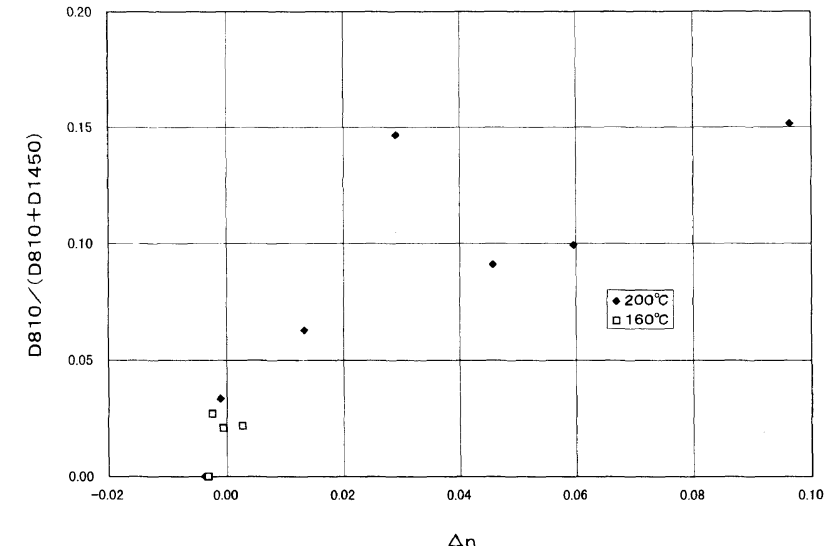

Figure 6. Relationship of D810/D810+D1450) with birefringence for the heat treated precursor fibers.

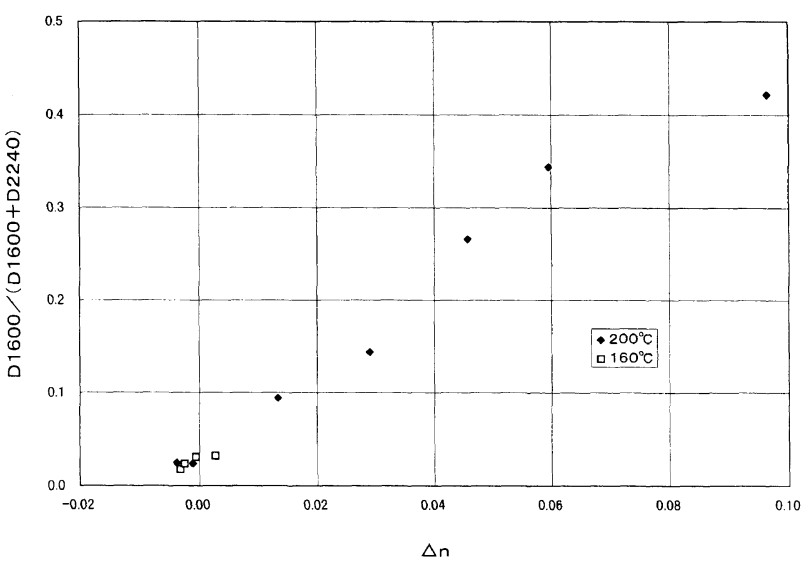

Figure 7. Relationship of D1600/(D1600+D2240) with birefringence for the heat treated precursor fibers.

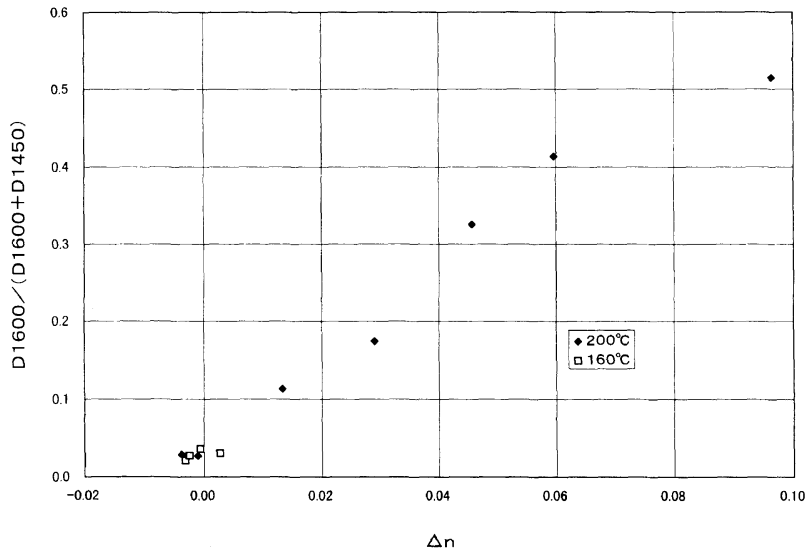

Figure 8. Relationship of D1600/(D1600+D1450) with birefringence for the heat treated precursor fibers.<smiles>CC(C)C(C)C(C)C(C)C(C)C(C)C1C(=N)OC(=O)C(C)(C)C1C</smiles>

(b)<smiles></smiles>

(d)<smiles>Cc1cc2c(=O)c3cc(C(C)C(C)C#N)c(N)nc3[nH]c2nc1C</smiles>

Figure 9. Structural changes during the heat treatment in air at $200^{\circ} \mathrm{C}$. 
by such a short time heat treatment and exists as the resonance structure shown in Figure 9(c). The dehydrogenation reaction occurs in this structure and the fully aromatic cyclized structure is formed and develops as schematically shown in Figure 9.

In conclusion, we may say definitely that when the precursor acrylic fibers are heat treated in fixed length in air atmosphere, the birefringence of fiber increases from slightly negative to highly positive because of the development of the stabilized fully heteroaromatic or partially aromatic structure as shown in Figure 9. With the development of the stabilized structure, the length of the conjugated structure becomes longer along the molecular chain. This increases the birefringence as a result of the increase of the polarizability along the fiber axis direction. Thorn and Marjoram ${ }^{18}$ related the birefringence change to the change of the chain orientation estimated from the X-ray diffraction data. But in our study the samples heat-treated at a lower temperature of $200^{\circ} \mathrm{C}$ show remarkable birefringence change although the X-ray orientation is not different very much before and after treatment. Therefore the large change in the birefringence should be related, not to orientation change, but to chemical structural change of the acrylic fiber as discussed above.

\section{REFERENCES}

1. A. Gupta, D. K. Paliwal, and P. Bajaj, J. Macromol. Sci., C31, 1 (1991).
2. Z. Bashir, Carbon, 29, 1081 (1991).

3. H. Kakida, K. Tashiro, and M. Kobayashi, Polym. J., 28, 30 (1996).

4. J. B. Donnet and R. C. Bansal, in "Carbon Fiber," 2nd ed, Marcel Dekker, New York, N.Y., 1990.

5. R. C. Houtz, Textile Res. J., 20, 786 (1950).

6. N. Grassie, J. N. Hay, and I. C. McNeill, J. Polym. Sci., 31, 205 (1958).

7. W. J. Burlant and J. L. Parsons, J. Polym. Sci., 22, 249 (1956).

8. E. M. LaCombe, J. Polym. Sci., 24, 152 (1957).

9. A. Tager, in "Physical Chemistry of Polymers," (English edition), Mir Publishers, Moscow, 1978.

10. J. Schurz, J. Polym. Sci., 28, 438 (1958).

11. A. A. Berlin, A. M. Dubinskaya, and Yu. Sh. Moshkovski, Vysokomol. Soedin., 6, 1938 (1964); Polym. Sci. USSR, 6, 2145 (1966).

12. W. Fester, Textil Rundschau, 20, 1 (1965)

13. W. Fester, in "Macromolecular Chemistry," Prague [J. Polym. Sci. Part C, Polym. Symp., 16, 755, 1965)], O. Wichterle and B. Sedlacek, Chairmen, Interscience, New York, N.Y., 1967, p 755.

14. H. Kakida and K. Tashiro, Polym. J., 29, 353 (1997).

15. H. Kakida and K. Tashiro, Polym. J., 29, 557 (1997).

16. H. Kakida, K. Sanbuichi, Y. Fujii, and K. Tashiro, Polym. J., to be submitted.

17. H. Kakida and K. Tashiro, Polym. J., 30, 463 (1998).

18. D. J. Thorn and J. R. Marjoram, J. Appl. Polym. Sci., 16, 1357 (1972).

19. A. N. J. Heyn, Text. Res. J., 22, 513 (1952).

20. W. E. Morton and J. W. S. Hearle, in "Physical Properties of Textile Fibers," Textile Institute and Butterworths, Manchester and London, 1962, p 539.

21. H. S. Fochler, J. R. Moony, L. E. Ball, R. D. Boyer, and J. G. Grasseli, Spectrochim. Acta, 41A, 271 (1985).

22. G. T. Sivy and M. M. Coleman, Carbon, 19, 127 (1981). 